\title{
LA REVISTA PERUANA DE MEDICINA EXPERIMENTAL Y SALUD PÚBLICA EN EL CONTEXTO POLÍTICO NACIONAL
}

\author{
THE PERUVIAN JOURNAL OF EXPERIMENTAL MEDICINE AND PUBLIC HEALTH WITHIN \\ THE NATIONAL POLITICAL CONTEXT
}

\author{
Zuño Burstein ${ }^{1, a}$, Franco Romaní1,b
}

En el editorial de la Revista Peruana de Medicina Experimental y Salud Pública (RPMESP) del primer número del 2017 manifestamos nuestra preocupación, ya expresada el año anterior ${ }^{(1,2)}$, sobre la severa y sin precedente crisis política que acontece en nuestro país. Dicha situación, sumada a los desastres naturales producidos a inicios de año, repercutieron negativamente en las áreas en las cuales nos encontramos involucrados, como el sector salud y educación.

Dentro de la coyuntura nacional, a fines del 2017 se inició un proceso de vacancia contra el presidente de la república, el economista Pedro Pablo Kuczynsky, personaje público que motivó el editorial del primer número del año pasado ${ }^{(2)}$. La inestabilidad política continuó y propició la renuncia del presidente de la república, con ello el primer vicepresidente, el ingeniero Martín Vizcarra Cornejo asumió la presidencia, lo cual generará relevos en el consejo de ministros. Desde julio del 2016, ocurrieron tres cambios de ministros de salud, la doctora Patricia García Funegra fue reemplazada por el oficial en retiro de la marina peruana Fernando D'Alessio Ipinza y recientemente lo sucedió el médico Abel Salinas Rivas; y los recientes acontecimientos indican que un cuarto ministro de salud asumirá la cartera, todo en un periodo menor de dos años.

Por otro lado, en el Instituto Nacional de Salud (INS), brazo científico del Ministerio de Salud, se produjeron durante el 2017 constantes cambios de jefes institucionales con la designación sucesiva de cinco profesionales; el médico Luis Suárez Ognio fue reemplazado por el médico Álvaro Whittembury Vlásica, posteriormente asumió la jefatura la médica María Luisa Mirabal, luego la médica Silvia Pessah Elijay, para finalmente el 9 de octubre del 2017 el médico César Cabezas Sánchez fue designado jefe institucional.

A pesar de este contexto político inestable, la RPMESP ha mantenido su capacidad de gestión y calidad cientifica, lo cual ha sido posible gracias al esfuerzo de nuestro equipo editorial y su compromiso con la difusión científica en el campo de la salud pública. Este compromiso ha sido gratificantemente reconocido durante el año pasado, así, el 23 de noviembre en ceremonia pública, la RPMESP recibió el Premio de Excelencia Elsevier 2017.

Igualmente, la RPMESP fue considerada e invitada como la publicación científica biomédica peruana más destacada a diversos eventos científicos, por ejemplo, en setiembre del 2017 participó en el IV Congreso Nacional de Gestión de la Investigación, organizado por la Pontificia Universidad Católica del Perú, y en noviembre, en el Seminario de gestión de la investigación y el posgrado en la universidad pública peruana, organizado por la Universidad Nacional Mayor de San Marcos.

Con el objetivo de mantener la capacidad de gestión editorial, el 26 de diciembre del 2017 se emitió la Resolución Jefatural que realizó reajustes necesarios en la composición del comité editor de la RPMESP. Entre dichos cambios; el médico Alonso Soto Tarazona por sobre carga laboral dejó el cargo de editor científico, sin embargo, se mantiene como miembro del comité editor. En su reemplazo asumió el médico Franco Romaní Romaní, investigador científico del INS, y director ejecutivo de la Oficina Ejecutiva de Transferencia Tecnológica y Capacitación.

El médico Akram Hernández Vásquez fue incorporado al grupo de editores adjuntos constituido por los médicos Hugo Arroyo Hernández y Jhonnel Alarco Urquizo. Continúa el valioso apoyo de la Lic. Bertha Huarez Sosa en el cargo de asistente editorial. El médico Leonardo Rojas Mezarina, fue incorporado como coordinador técnico administrativo de la RPMESP en su condición de director general de la Oficina General de Información y Sistemas del INS, junto al médico Daniel Espinoza Herrera como director ejecutivo de la Oficina Ejecutiva de Información y Documentación Científica del INS.

\footnotetext{
Revista Peruana de Medicina Experimental y Salud Pública, Instituto Nacional de Salud, Lima, Perú.

Director; ${ }^{\mathrm{b}}$ editor científico.

Recibido: 26/02/2018 Aprobado: 28/02/2018 En línea: 05/04/2018
}

Citar como: Burstein Z, Romaní F. La Revista Peruana de Medicina Experimental y Salud Pública en el contexto político nacional. Rev Peru Med Exp Salud Publica. 2018;35(1):5-6. doi: 10.17843/rpmesp.2018.351.3593 
El equipo editorial se desempeña bajo la orientación del director y del editor general de la RPMESP, además el comité editor se encuentra conformado por profesionales de reconocida experiencia en publicaciones científicas. Algunos miembros del comité editor, por disponibilidad de tiempo y en virtud de su experticia y contribución científica, han sido reubicados al consejo consultivo, el cual actualmente ha quedado constituido por personalidades científicas destacadas a nivel nacional e internacional que, en forma ad honorem, al igual que muchos miembros del comité editor, se desempeñan como asesores de la RPMESP.

El 2017, la RPMESP ha cumplido satisfactoriamente con el cronograma de publicaciones. En el volumen 34 del 2017, 120 artículos fueron publicados de los cuales $32(26,7 \%$ del total de artículos) fueron artículos originales y 22 (18,3\%) fueron originales breves. Por otro lado, fueron publicadas 21 cartas al editor (17,5\%), lo cual refleja la interacción de la comunidad científica fomentada por nuestra revista. Un aspecto importante para la RPMESP, es haber logrado que la proporción de artículos originales con respecto al total de publicaciones se mantenga por encima del $40 \%$. Dicho logro es alcanzado, con tendencia creciente, desde el 2014 $(41,1 \%)$, siendo $45 \%$ para el 2017.

Cabe mencionar que el volumen 34 en su versión electrónica, incluye como suplemento los resúmenes científicos presentados en el XI Congreso Científico Internacional del INS, los cuales en virtud de su calidad científica fueron aceptados por el comité organizador. Esta iniciativa permite brindar una mayor visibilidad a las investigaciones realizadas por profesionales de todo el Perú, y los alienta a continuar con el desarrollo de sus investigaciones.

En forma complementaria al proceso editorial de la RPMESP, sus miembros editores han desarrollado activamente una serie de asistencias técnicas, que buscan contribuir a desarrollar competencias en redacción científica y fomentar la publicación científica. Al respecto, organizamos un curso de redacción de artículos científicos dirigido a investigadores de la Universidad Nacional de la Amazonía Peruana. Como parte del Congreso Científico del INS, se realizó el «Seminario de publicación y redacción científica» en coorganización con el Instituto Nacional de Enfermedades Neoplásicas, el cual estuvo dirigido a investigadores y estudiantes de pregrado y posgrado; y el «Encuentro de editores científicos» el cual buscó crear un espacio de interacción de editores de las diferentes revistas científicas biomédicas nacionales para el intercambio de buenas prácticas y experiencias.

No queremos dejar pasar la oportunidad para agradecer a los revisores, quienes, con su valiosa contribución ad honorem en la revisión de los manuscritos, contribuyen a mejorar la calidad científica de nuestras publicaciones. En total contribuyeron 169 revisores de 17 nacionalidades diferentes, principalmente de Perú (46,7 \%), España (13,6 \%), México $(11,2 \%)$ y Chile $(6,5 \%)$.
Durante el año 2017 se programó y publicó en cada número de la RPMESP los siguientes temas que dieron origen a sendas conferencias conjuntas con la Academia Nacional de Medicina (ANM) bajo la denominación de Simposios. El primer número tuvo como temática «Obesidad como problema de salud pública» y cómo editor invitado al Dr. Miguel Malo (asesor de la Organización Panamericana de Salud), el segundo número desarrolló el simposio «Antropología de la salud» cuyo editor invitado fue el Dr. Michael Knipper (Universidad de Giessen), el tercer número abordó el tema "Evaluación de programas de salud» y el editor invitado fue el Dr. Alfonso Gutiérrez (Ministerio de Economía y Finanzas del Perú), el último número fue dedicado a «Anemia infantil», siendo el editor invitado la Dra. Nelly Zavaleta (INS).

Las conferencias conjuntas con la ANM buscan obtener conclusiones y recomendaciones dirigidas a los hacedores de políticas y tomadores de decisión sobre los temas tratados. Participaron en total 542 personas, siendo el simposio sobre Obesidad como problema de salud pública, el de mayor atención (240 asistentes), seguido por Anemia infantil (129 asistentes), Evaluación de programas de salud (101 asistentes) y Antropología de la salud con 72 .

Para el 2018 se ha programado y comprometido los siguientes temas para los cuatro números de la RPMESP: el primer número aborda como tema de simposio «Resistencia Antimicrobiana», con el editor invitado Dr. Martín Yagui Moscoso del INS, la fecha programada para la presentación de la revista y la conferencia conjunta es el 24 de abril. El segundo número tiene como tema de simposio «Agua y Salud» con la editora invitada Dra. María del Carmen Gastañaga del INS, la recepción de artículos para este número vence el cuatro de abril y la conferencia conjunta será el 24 de julio. El tercer número dedicará su simposio al tema «Investigación en Políticas y Sistemas de Salud» la fecha de cierre de recepción de artículos es el 27 de junio y la conferencia conjunta el 23 de octubre. Por último, el cuarto tema será "Una Salud» con el editor invitado Dra. Mónica Guardo de la Organización Panamericana de Salud en Perú, la recepción de artículos será hasta el 19 de septiembre y la conferencia conjunta se realizará el 11 de diciembre

La RPMESP reitera la invitación para que los profesionales de salud del Perú y las Américas colaboren con sus manuscritos en las diversas secciones con las que contamos. Los manuscritos enviados deberán cumplir con los requerimientos exigidos en las instrucciones para los autores, para que sean evaluados, calificados por pares expertos nacionales e internacionales y aprobados para su publicación. Así, el INS y la RPMESP mantienen su meta primordial de contribuir con el mejoramiento de la salud y el bienestar de la población peruana mediante la promoción, desarrollo y difusión de la investigación científica.

\section{REFERENCIAS BIBLIOGRÁFICAS}

1. Burstein Z, Cabezas C. La Revista Peruana de Medicina Experimental y Salud Pública continúa al servicio de la salud pública del Perú y Latinoamé- rica. Rev Peru Med Exp Salud Pública. 2016;33(1):10-12.

2. Burstein $\mathrm{Z}$, Apreciación critica a la gestión 2016 y perspectivas al nuevo año 2017 de la Revista Peruana de Medicina Experimental y Salud Pública. Rev Peru Med Exp Salud Pública. 2017;34(1):7-10. 